holy oils, holy water and other aids to perform healing. Within these categories, there may be subcategories (e.g. herbalists who specialise as traditional bonesetters). These healers typically work within communities where they are known to their patients.

\section{Ethical considerations}

This article followed all ethical standards for a research without direct contact with human or animal subjects.

\section{Traditional medicine practice development in Ghana: From informal community practice to formalised care}

As previously mentioned, indigenous healing processes were delegitimised and devalued during colonial times. ${ }^{8}$ In fact, under British rule in Ghana, the Native Customs Regulation Ordinance of 1878 banned indigenous healing practices outright. ${ }^{9}$ In addition to these official rules, the nature of cultural practice meant that indigenous systems evolved as cultures developed and thus were often context-specific. This made it difficult to create a comprehensive picture of indigenous healing practices in Ghana.

For a long time, there was limited knowledge on the work of indigenous healers in Ghana generally. The limited knowledge also made recognition and regulation of their work difficult to accomplish. With the attainment of political independence from colonial rule in the late 1950s, efforts were made to recognise and promote the work of indigenous healers in Ghana. In 1960, the first president of Ghana, Osagyefo Dr Kwame Nkrumah initiated the formal set-up of the Ghana Psychic and Traditional Healing Association, whose mandate was 'to promote the study of herbalism and psychicism' in Ghana for application in the public health sector. ${ }^{10,11}$ A further aim for the establishment of the association was to provide organisation to indigenous healers, as well as to lend some respectability to indigenous medicine practice in Ghana, in contrast to the disdain that had existed during colonisation. Thirdly, the association was expected to eventually facilitate indigenous healers working alongside 'orthodox practitioners' to treat illnesses, especially those for which there was no biomedical cure at the time. ${ }^{9,11}$

This inaugural group experienced many challenges in achieving its mandate as a result of differences in beliefs and orientation. Because of these challenges, several splinter groups emerged, such as the Plant Medicine Association, the Ghana Muslim Healers Association and the Ghana Psychic Healers Association. Individuals whose orientations were considered similar formed these splinter groups, and many of them still exist today. According to Mensah, ${ }^{10}$ presently there are six major indigenous healers' association in Ghana, with numerous subgroups.
By 1999, the fragmented nature of organised traditional medicine practitioners' groups had achieved very little by way of their intended mandate. Thus, in November 1999 further efforts were made to unite the different associations through the establishment of a new body called the Ghana Federation of Traditional Medicine Practitioners' Associations (GHAFTRAM). The Ghana Federation of Traditional Medicine Practitioners' Associations was formed to serve as a unifying body for the different categories of indigenous healers. They further served as a liaison between the healers and the Ministry of Health.

In 1991, the Ministry of Health established a Traditional Medicine Directorate (later renamed the Traditional and Alternative Medicine Directorate) as a formal division. ${ }^{12} \mathrm{~A}$ new law of the Food and Drugs Board (PNDC Law 305B) was also introduced in 1992 to regulate the manufacture and sale of herbal medications on the market. These, together with the establishment of GHAFTRAM and the development of the Ministry of Health's National Strategic Plan for Traditional Medicine Development in 1999, facilitated the enactment of the Traditional Medicine Practice Act (Act 575) in 2000. This act mandated the formation of the Traditional Medical Practice Council (which was officially established in 2010) to license, regulate and oversee the work of traditional and alternative medicine practitioners in Ghana. ${ }^{13}$

The official recognition of alternative medicine in Ghana has therefore undergone some transformation over the years. Currently, the work of indigenous healers is governed by the Traditional and Alternative Medicine Division of the Ministry of Health, GHAFTRAM, the Food and Drugs Authority, and the Traditional Medical Practice Council. ${ }^{5}$ Specific to mental health, the newly passed Mental Health Act (Act 846 of 2012) refers to working with organised bodies (such as GHAFTRAM) to promote access to mental healthcare in Ghana.

Much of the effort at formal organisation of indigenous medicine has focused on the work of diviners and herbalists and, to a small extent, the Muslim healers. However, there is less official organisation for the work of Christian faith healers. Christian faith healers are predominantly Pentecostal or charismatic in orientation. As such, healing is considered an integral part of their religious expression. Although such churches are required to be registered with the Ghana Pentecostal and Charismatic Council, the healing centres (called prayer camps) are not registered separately as healthcare facilities, primarily because their activities may also include prayers for non-health problems. This presents difficulties for regulating and monitoring their work.

Although the efforts at organising alternative healers in Ghana have continued for some years, there are a significant number of healers who are not officially registered under any organisational body. Some reasons that have been suggested for this include the need for secrecy in the work of some categories of healers (e.g. the fetish priests) and, 
as discussed, the intertwining of core religious activities with health outcomes in some forms of practice. ${ }^{14,15}$

\section{Collaboration between biomedical institutions and indigenous healers in Ghana}

There have been many calls for the integration of the different forms of healthcare in Ghana, as in other countries. ${ }^{16}$ As we have discussed, various factors account for the widespread use of alternative medicine in Ghana, including human resource constraints in the biomedical sector, as well as availability and perceived accessibility of indigenous and faith healers. ${ }^{17}$ As a result, there have been calls for and attempts at collaboration between the biomedical system and various alternative systems. ${ }^{18}$

One of the early recorded collaborations between biomedicine and herbal medicine in Ghana was in the MampongAkwapim District in the 1940s. This was an initiative of a medical doctor, Dr Oku Ampofo, who left government practice to set up a private practice with the aim of providing a recognised space for herbalists to practice alongside doctors. ${ }^{19}$ This partnership was considered quite successful, and through this collaboration Dr Ampofo compiled lists of medicinal plants and herbal remedies that were commonly used by herbalists in the region. This initiative is credited as being foundational for the establishment of the Centre for Scientific Research into Plant Medicine (CSRPM) in Ghana in $1975 .{ }^{19}$

Following the successful partnership in the MampongAkwapim area, the Ministry of Health, together with the CSRPM and other local stakeholders, developed the Primary Health Training for Indigenous Healers programme (PRHETIH $)^{11}$ in Techiman in the early 1980s. This programme aimed to provide biomedical primary healthcare training for indigenous healers to improve their methods. It sought to widen the collaboration between biomedicine and other healers and therefore included herbalists, priests, traditional birth attendants and traditional surgeons. Although the programme was met with much enthusiasm, an evaluation performed 10 years later showed that the healers' methods had not changed..$^{20}$ Aries et al. ${ }^{21}$ speculated that the PRHETIH programme failed to achieve its intended purpose because of the different pathophysiological orientations that existed between the different classes of healers, a difference that had not been taken into account when the PRHETIH programme was developed. As Kpobi and Swartz ${ }^{22}$ explained, the beliefs about what constituted an illness differed based on the cultural and religious orientation of the healers. Without acknowledging this difference, integrating the two systems of care will be difficult. Konadu ${ }^{6}$ appeared to agree with this assertion, referring to the calls for integration as 'an illusion'. According to him, the unequal political and cultural power relations would result in the forceful assimilation of one system into the other, leading to the eventual disappearance of the weaker group - most likely, the indigenous healers. ${ }^{6,23}$
Despite the perceived failure of the PRHETIH programme, other attempts at establishing collaborations have been reported..$^{24,25,26,27}$ In 2011, the Ministry of Health, in a bid to begin integration of herbal and biomedical facilities, undertook a pilot study that introduced herbal units at hospitals. Small herbal medicine units were established in 17 hospitals across the country to provide patients with the option of purchasing certified herbal remedies. ${ }^{28}$ In reviewing this programme in one hospital in Kumasi 5 years later, Boateng et $a .^{28}$ reported that the herbal and biomedical sectors at that hospital were running parallel to each other rather than being integrated with each other. Further, only a few patients were aware of the presence of the herbal unit. The authors speculated that this was likely because of the absence of clear policies and guidelines on referral between the two groups of healthcare providers. ${ }^{28}$ Thus, the different units existed separately, without working together as had been desired.

These reports are examples of collaborative programmes that were developed largely for primary health partnerships with traditional healers. With regard to mental health collaborations, attempts at integration have also been generally unsuccessful. Exploring the factors that hinder or promote partnerships between indigenous medicine practitioners and biomedical practitioners, Ae-Ngibise et al. ${ }^{17}$ observed that mutual distrust and scepticism, limited knowledge about practices and concerns about human rights abuses were cited by different stakeholders as important barriers that have prevented successful collaborations between mental health professionals and indigenous or faith healers. The stakeholders in this study included indigenous healers, biomedical practitioners and policymakers. Stakeholders in other studies ${ }^{29}$ expressed similar sentiments. For instance, Doku et al. ${ }^{30}$ reported comparable stakeholder views but also included inadequate policy implementation as a factor that affected integration of mental health services in Ghana. Awenva et al. ${ }^{31}$ identified barriers to policy implementation, including a lack of political interest in mental health, inadequate policy dissemination and an absence of researchbased evidence for reform. The participants further advocated for collaborative efforts to be more intersectoral by including the educational, legal and development sectors of the country in order to be successful.

Osafo $^{32}$ similarly examined the possibility of a collaborative network between mental health professionals and religious leaders in Accra. In addition to the reasons we have already cited, religious healers also decried biomedicine's aversion to creating space for spiritual conditions, resulting in helpseeking stigma and territoriality. In order to achieve the desired integration of mental health service in Ghana, Osafo ${ }^{32}$ proposed a task-sharing model that incorporates a mutual appreciation for the work of the other.

This desire for mutual appreciation has been reported by indigenous and faith healers in other studies. There was a general perception among healers that biomedical professionals regarded them with some level of disdain, 
often dismissing their beliefs and methods. ${ }^{17,33,34}$ In one study, staff at prayer camps indicated a keen interest in working with the biomedical field to provide technical and infrastructural support (such as medication) but desired to do so only if they were treated with respect. ${ }^{35}$ In a related study, Ofori-Atta et al. ${ }^{36}$ worked with one prayer camp to provide biomedical care in addition to the standard spiritual care to a randomised sample of patients at the camp. According to the authors, the goal was to show staff at the camp the effectiveness of biomedical methods and to encourage collaboration between the two systems of care. Although the patients who were given medical treatment had better outcomes in the short term than their control counterparts, the authors found no significant change in the methods and attitudes of the staff at the camp. This lends support to the arguments of authors such as $\operatorname{Read}^{37,38}$ that indigenous and faith healers are aware of the usefulness of biomedical medications for short-term relief of symptoms but do not perceive biomedicine to provide better long-term outcomes.

In addition, the methods employed by Ofori-Atta and colleagues $^{36}$ did not appear to seek an understanding of the prayer camp methods; instead, they appeared to simply demonstrate biomedicine's prowess to the religious healers. While this was a unique initiative in the drive for collaboration, it echoes Konadu's ${ }^{6}$ sentiments about the unequal power relations making integration difficult. In this study too, the prayer camp staff appeared to recognise the benefits of medication but felt that it did not provide the expected outcomes in the long run. Other studies with biomedical workers have shown similar attitudes towards the work of faith healers. The healthcare staff often recognised the usefulness of the spiritual engagement that religious healers employed but were concerned about what they perceived as subjective and unstandardised methods, some of which were considered abusive. ${ }^{17,35}$

Examining the role of indigenous and faith healers' perceived power in the treatment of mental illness in Ghana, Read ${ }^{38}$ argued that a critical element to be considered in the dialogue on integrating mental health services was the practitioners' beliefs surrounding the power of each system of care to heal the patient. Collaboration between the different systems would need to take into consideration the contested notions of healing power held by different practitioners, in order to be successful. $\operatorname{Read}^{38}$ reasoned that indigenous and faith healers often position themselves as possessing healing power that can provide longer-lasting solutions to patients' problems than biomedicine. On the other hand, biomedicine was perceived by the healers to possess recognition and legitimacy in the national health framework.

Taking this assertion a step further, Kpobi and Swartz ${ }^{39}$ analysed the perceptions of power and positioning of different categories of indigenous healers, as well as how these self-perceptions influenced the willingness to collaborate with biomedicine. They identified that healers who perceived themselves as possessing abilities that were most powerful for providing healing (e.g. pastors and herbalists) were also most interested in collaborating with other systems of care. The authors argued that this was possibly because of these healers' desire for recognition and formal acceptance, such as that biomedical systems appear to possess. On the other hand, those healers who considered themselves merely as conduits of a higher power did not desire formal collaboration. These healers were arguably not desirous of formal recognition because they believed their work was not a reflection of their own abilities but rather a reflection of the power of the deity they represented. Such competing ideas about power and place in the healing hierarchy would influence the willingness to collaborate. In order to achieve the desired collaboration, there needs to be recognition of the differing illness beliefs of the healers, as well as their different positioning with respect to healing power and their willingness to collaborate.

\section{Conclusion}

The field of alternative medical care in Ghana has undergone various transformations over the years. Despite the many processes that have occurred, non-biomedical healthcare remains a popular option for a significant number of Ghanaians. ${ }^{40}$ Despite this popularity, many attempts to establish integrated healthcare that affords patients access to both biomedical and non-biomedical options have seen little success. Furthermore, the continued scepticism towards indigenous practices has resulted in difficulties in regulating, monitoring and improving indigenous care. Although initial collaboration programmes may have stalled, they may present valuable lessons on the way forward. In order to attain effective collaborative care in all spheres of healthcare, programmes and policies must be built on accurate understandings of how key stakeholders are situated (and indeed situate themselves) in the conversation.

\section{Acknowledgements}

The authors extend their appreciation to Ms. Jacqueline Gamble for the editing work.

\section{Competing interests}

The authors declare that they have no financial or personal relationships that may have inappropriately influenced them in writing this article.

\section{Authors' contributions}

L.K. and L.S. together conceptualised the article. L.K. conducted the literature search, analysis and interpretation of the data and drafted the manuscript, all under the supervision and correction of L.S. Both authors read and approved the final manuscript.

\section{Funding information}

This article forms part of the doctoral dissertation of the first author, funded by the Graduate School of the Arts and Social 
Sciences at Stellenbosch University. Further funding was provided for the second author (L.S.) by the National Research Foundation (NRF) of South Africa under grant number 85423

\section{Data availability statement}

Data sharing is not applicable to this article as no new data were created or analysed in this study.

\section{Disclaimer}

The content of this article is the sole responsibility of the authors and does not necessarily represent the official views of Stellenbosch University or the National Research Foundation (NRF). Neither the university nor the NRF played any official role in the design of the study; in collection, analysis and interpretation of data; or in writing the manuscript.

\section{References}

1. Busia K. Medical provision in Africa: Past and present. Phytother Res. 2005;19: 919-923. https://doi.org/10.1002/ptr.1775

2. Jahoda G. Traditional healers and other institutions concerned with mental illness in Ghana. Int J Psychiatry. 1961;7:245-268. https://doi.org/10.1002/ ptr.1775

3. Twumasi PA. Medical systems in Ghana: A study in medical sociology. Tema: Ghana Publishing; 1975.

4. Hampshire KR, Owusu SA. Grandfathers, Google and dreams: Medical pluralism globalization and new healing encounters in Ghana. Med Anthropol. 2013;32(3): 247-265. https://doi.org/10.1080/01459740.2012.69274

5. Addy ME. Putting science into the art of healing with herbs. Accra: Ghana Universities Press; 2003.

6. Konadu K. Indigenous medicine and knowledge in African society. New York Routledge; 2007.

7. Tabi MM, Powell M, Hodnicki D. Use of traditional healers and modern medicine in Ghana. Int Nurs Rev. 2006;53:52-58. https://doi.org/10.1111/j.1466-7657. 2006.00444.x

8. Barimah KB. Traditional healers in Ghana: So near to the people, yet so far away from basic health care system. Humanitas Med. 2016;6(2):e9. https://doi.org/ 10.5667/tang.2016.0004

9. Senah K. In sickness and in health: Globalization and health care delivery in Ghana. Res Rev Inst Afr Stud. 2001;17:83-89. https://doi.org/10.4314/rrias. v17i1.22902

10. Mensah EN. Status of traditional medicine development in Ghana. Paper presented at: the meeting of Society of Ghana Women Medical and Dental Practitioners, Accra, 27th April, 2011

11. Warren D, Bora G, Tregoning M, Kliewer M. Ghanaian policy towards indigenous healers - The case of the primary health training for indigenous healers (PRHETIH) program. Soc Sci Med. 1982;16:1873-1881. https://doi.org/10.1016/0277-9536 (82) $90448-8$

12. Kofi-Tsekpo M. Institutionalization of African traditional medicine in health care systems in Africa. Afr J Health Sci. 2004;11(1/2):i-ii.

13. Senah KA, Adusei JK, Akor SA. A baseline study into traditional medicine practice in Ghana. Ghana: Ministry of Health/DANIDA; 2001.

14. Abukari K. Theorizing health and illness: The role of language and secrecy in traditional healing among the Dagomba. Int J Humanit Soc Sci. 2016;6(2) 73-83.

15. Mokgobi MG. Towards integration of traditional healing and western healing Is this a remote possibility? Afr J Phy Health Edu Recreat Dance. 2013;(Suppl 1): 47-57.

16. World Health Organization. Traditional medicine strategy 2014-2023. Geneva: World Health Organization; 2013.
17. Ae-Ngibise K, Cooper S, Adiibokah E, Akpalu B, Lund C, Doku V. 'Whether you like it or not people with mental problems are going to go to them': A qualitative exploration into the widespread use of traditional and faith healers in the provision of mental health care in Ghana. Int Rev Psychiatry. 2010;22:558-567.
https://doi.org/0.3109/09540261.2010.536149

8. Akpalu B, Lund C, Doku V, et al. Scaling up community-based services and improving quality of care in the state psychiatric hospitals: The way forward for Ghana. Afr J Psychiatry. 2010;13:109-115. https://doi.org/10.4314/ajpsy.v13i2.54356

19. Evans-Anfom E. Traditional medicine in Ghana: Practice, problems and prospects. Accra: Academy of Arts and Sciences; 1986.

20. Ventevogel P. Whiteman's things: Training and detraining healers in Ghana. Amsterdam: Het Spinhuis; 1996.

21. Aries $\mathrm{MJH}$, Joosten $\mathrm{H}$, Wegdam $\mathrm{HHJ}$, Van der Geest $\mathrm{S}$. Fracture treatment by bonesetters in central Ghana: Patients explain their choices and experiences. Trop Med Int Health. 2007:12(4):564-574. https://doi.org/10.1111/j.1365-3156. Trop Med Int

22. Kpobi L, Swartz L. "That is how the real mad people behave": Beliefs about and treatment of mental disorders by traditional medicine men in Accra, Ghana. Int J Soc Psychiatry. 2018;64(4):309-316. https://doi.org/10.1177/0020764018763705

23. Van der Geest S, Krause K. Introduction: Studying health and health care in Ghana. Ghana Studies. 2014;15-16:7-39.

24. Amoah SKS, Sandjo LP, Bazzo ML, Leite SN, Biavatti MW. Herbalists, traditiona healers and pharmacists: A view of the tuberculosis in Ghana. Braz J Pharmacogn. 2014;24:89-95. https://doi.org/10.1590/0102-695X2014241405

25. deGraft-Aikins A. Exploring biomedical and ethnomedical representations of diabetes in Ghana and the scope for cross-professional collaboration: A social psychological approach to health policy. Soc Sci Inf. 2002;41:625-652. https://doi org/10.1177/0539018402041004007

26. Krah E, Kruijf J, Ragno L. Integrating traditional healers into the health care system Challenges and opportunities in rural northern Ghana. J Community Health. 2018;43(1):157-163. https://doi.org/10.1007/s10900-017-0398-4

27. O'Brien KS, Soliman AS, Annan K, Lartey RN, Awuah B, Merajver SD. Traditional herbalists and cancer management in Kumasi, Ghana. J Cancer Educ. 2012;27(3):573-579. https://doi.org/10.1007/s13187-012-0370-z

28. Boateng MA, Danso-Appiah A, Turkson BK, Tersbol BP. Integrating biomedical and herbal medicine in Ghana - Experiences from the Kumasi South Hospital: A qualitative study. BMC Complement Altern Med. 2016;16:189-196. https://doi. org/10.1186/s12906-016-1163-4

29. Van der Watt ASJ, Nortje G, Kola L, et al. Collaboration between biomedical and complementary and alternative care providers: Barriers and pathways. Qua Health Res. 2017;27(14):2177-2188. https://doi.org/10.1177/1049732317729342

30. Doku V, Ofori-Atta A, Akpalu B, et al. Stakeholders' perceptions of the main challenges facing Ghana's mental health care system: A qualitative analysis. Int J Cult Ment Health. 2011;4(1):8-22. https://doi.org/10.1080/17542863.2010.503038

31. Awenva D, Read U, Ofori-Atta AL, et al. From mental health policy development in Ghana to implementation: What are the barriers? Afr J Psychiatry. 2010;13(3): 184-191.

32. Osafo J. Seeking paths for collaboration between religious leaders and mental health professionals in Ghana. Pastoral Psychol. 2016;65:493-508. https://doi. org/10.1007/s11089-016-0703-7

33. Osafo J, Agyapong M, Asamoah MK. Exploring the nature of treatment regimen for mentally ill persons by neo-prophetic ministers in Ghana. Int J Cult Ment Health. 2015;8(3):325-339. https://doi.org/10.1080/17542863.2014.973428

34. Asamoah MK, Osafo J, Agyapong I. The role of Pentecostal clergy in mental healthcare delivery in Ghana. Ment Health Relig Cult. 2014;17(6):601-604. https://doi. org/10.1080/13674676.2013.871628

35. Arias D, Taylor L, Ofori-Atta A, Bradley EH. Prayer camps and biomedical care in Ghana: Is collaboration in mental health care possible? PLoS One. 2016;11(9): e0162305. https://doi.org/10.1371/journal.pone.0162305

36. Ofori-Atta A, Attafuah J, Jack $\mathrm{H}$, et al. Joining psychiatric care and faith healing in prayer camp in Ghana: Randomised trial. Br J Psychiatry. 2018;212:34-41. https:// doi.org/10.1192/bjp.2017.12

37. Read UM. 'I want the one that will heal me completely so it won't come back again': The limits of antipsychotic medication in rural Ghana. Transcult Psychiatry. 2012;49(3-4):438-460. https://doi.org/10.1177/1363461512447070

38. Read UM. 'Doctor sickness' or 'Pastor sickness?' Contested domains of healing power in the treatment of mental illness in Kintampo, Ghana. In: Basu H, Littlewood $\mathrm{R}$, Steinforth AS, editors. Spirit and mind: Mental health at the intersection of religion and psychiatry. Munster, Germany: LIT Verlag, 2017; p. 167-188.

39. Kpobi L, Swartz L. Implications of healing power and positioning for collaboration between formal mental health services and traditional/alternative medicine: The case of Ghana. Glob Health Act. 2018;11(1):1445333. https://doi.org/10.1080/16 549716.2018.1445333

40. Ofori-Atta A, Read UM, Lund C. A situation analysis of mental health services and legislation in Ghana: Challenges for transformation. Afr J Psychiatry. 2010;13: 99-108. https://doi.org/10.4314/ajpsy.v13i2.54353 